\title{
Management of early-stage metastatic prostate cancer: appraisal of locoregional treatments and radiation therapy, with or without immunomodulation
}

\author{
Maria L Sandoval, Ammoren Dohm and Kosj Yamoah \\ 'Department of Radiation Oncology, H Lee Moffitt Cancer Center and Research Institute, Tampa, Florida, USA \\ Correspondence should be addressed to K Yamoah: Kosj.Yamoah@moffitt.org
}

This paper is part of a thematic review section celebrating 80 Years of Androgen Deprivation as a Treatment for Prostate Cancer. The guest editors for this section were Amina Zoubeidi and Paramita Ghosh.

\begin{abstract}
The current standard for the management of locally advanced and early stage metastatic prostate cancer relies on a backbone of androgen deprivation therapy (ADT) combined with radiotherapy $(\mathrm{RT})$, a regimen that at a glance appears relatively straightforward. The emergence of newer diagnostic, genomic and imaging modalities have allowed for better disease risk-stratification and opened avenues for the development of more patient-centered treatment strategies. This review aims to highlight the central role of RT as part of a multi-modal approach and discuss established and emerging data for the management of locally advanced disease, biochemical recurrence, and oligometastatic disease, as well as the use of immunotherapies and radio-isotopes. This review will also briefly discuss ongoing clinical trials that provide new insights into the paradigm shift in the management of locally advanced prostate cancer.
\end{abstract}

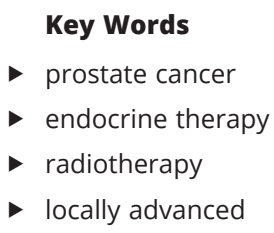

Endocrine-Related Cance (2021) 28, T109-T120

\section{Introduction}

With an estimated 190,000 new cases in the US in 2020, prostate cancer is the second most common cancer diagnosis in men following cutaneous cancer (https://www. cancer.org/cancer/prostate-cancer/about/key-statistics. $\mathrm{html})$. The year 2021 will mark the 80th year since the use of castration or androgen deprivation therapy (ADT) for prostate cancer which remains a cornerstone of treatment (Perlmutter \& Lepor 2007). Despite decades of advances, prostate cancer remains the second most common cause of cancer-related death in men, necessitating the development of new treatments.

Throughout the advances in the last several decades, RT has remained a pillar of treatment. The combination of RT with newer technologies, such as advanced assays, genomic risk stratification, and systemic therapies, which have allowed for more effective disease detection, risk stratification and treatment delivery. With the development of these tools, physicians are becoming better equipped to tailor treatments to individual patients and improve patient outcomes.

This review seeks to discuss some emerging roles and developments in RT-based modalities for the treatment of prostate cancer. Specifically, we will discuss emerging and established data for the use of RT in combination with hormonal therapy or immunotherapy, and therapeutic radioisotopes for locally advanced prostate cancer defined (c) 2021 Society for Endocrinology Published by Bioscientifica Ltd. Printed in Great Britain 
as locally advanced disease, biochemically recurrent disease, and oligometastatic disease.

\section{Locally advanced prostate cancer}

Per the Eighth Edition of the American Joint Committee on Cancer (AJCC) criteria, locally advanced prostate cancer is defined as T3 to T4 disease that has spread to involve one or several of the following: prostate capsule, seminal vesicles, regional pelvic lymph nodes, or adjacent organs such as the bladder, rectum, or pelvic wall. The Advanced Prostate Cancer Consensus Conference (APCCC) defines the locally advanced disease as node-positive nonmetastatic prostate cancer and distinguishes between clinical node-positive $(\mathrm{cN}+)$ disease and pathologic node-positive $(\mathrm{pN}+)$ as distinct entities (Gillessen et al. 2020).

For patients with cN+ disease, the Radiation Therapy Oncology Group (RTOG) 8531 study defined the standard of care by showing that the addition of long-term ADT to adjuvant RT resulted in a significant improvement in progression-free survival (PFS) (Pilepich et al. 2005). However, the long-term use of ADT has come into question because of cardiovascular side effects (Gillessen et al. 2020). Some study results have supported long-term ADT use (Bolla et al. 2009,2010); however, RTOG 9408 showed that RT and short-term use (4 months) were associated with decreased disease-specific mortality compared to RT alone (Jones et al. 2011). Post-hoc analysis of RTOG 9408 showed that the benefit of ADT was seen primarily among men with intermediate-risk disease, and short-term ADT was likely insufficient for men with high-risk disease. Consequently, given the mixed evidence regarding the duration of ADT, the consensus from APCCC for $\mathrm{cN} 1$ disease involves the radical locoregional treatment, whether in the form of surgery or RT plus ADT, without consensus for duration.

For patients undergoing prostatectomy, the detection of lymph node metastases is a poor prognostic sign for which adjuvant recommendations have not been clearly defined. In a large retrospective analysis of over 1300 postprostatectomy patients who were either placed under observation or given ADT \pm adjuvant RT, a significant increase in overall survival (OS) was found with ADT plus RT (Touijer et al. 2018).

With the known morbidity of RT or ADT, patient selection is an important consideration. Another series highlighted this importance by showing that the benefit of adjuvant RT in combination with ADT was limited to two groups: (1) patients with 1 or 2 positive nodes, pathological Gleason score between 7 and 10, and pT3b/4 disease or positive surgical margins and (2) patients with 3 or 4 positive nodes, regardless of other tumor characteristics (Abdollah et al. 2018). Therefore, patients with one or two involved nodes require further risk stratification before adding RT to their treatment regimen.

Given that the cornerstone treatment of locally advanced prostate cancer relies on a backbone of ADT and RT, there are several ongoing clinical trials that will continue to address the question of duration of therapy (NCT01122121 and NCT02799706) (Table 1). With the development of more sophisticated imaging modalities, the incidence of newly diagnosed locally advanced prostate cancer is likely to increase because of stage migration. This will continue to emphasize the importance of high-level evidence to guide the treatment of patients with locally advanced prostate cancer.

\section{Biochemical recurrence after locoregional treatment}

Biochemical recurrence (BCR) can occur as PSA recurrence after definitive local treatment or as PSA persistence after definitive treatment. Per the National Comprehensive Cancer Network (NCCN) definition, persistence is the failure of PSA to become undetectable after surgery, whereas the European Association of Urology (EUA) definition is PSA > $1.0 \mathrm{ng} / \mathrm{mL}$ within 4 to 8 weeks after surgery (Roach et al. 2006, Heidenreich et al. 2014, Pisansky et al. 2019, Van den Broeck et al. 2020) and has consistently been associated with poor oncological outcomes (Preisser et al. 2019). Risk factors for PSA persistence include higher pre-operative PSA levels, advanced pathological $\mathrm{T}$ stage and International Society of Urological Pathology (ISUP) grade, positive surgical margins, and pathologic nodepositive status (Preisser et al. 2019). Therefore, it is essential to use effective imaging for staging workup in order to help identify these patients. Currently, there is a prospective study that aims to assess whether PSMA PET/CT should replace conventional imaging for the initial staging of patients with high-risk features (Gleason grade group $\geq 3$, PSA $\geq 20 \mathrm{ng} / \mathrm{mL}$, or clinical stage $\geq \mathrm{T} 3$ ) (Hofman et al. 2018).

Another population with actively evolving clinical treatment strategies is patients who experience BCR after locoregional treatment. The definition of BCR varies based on prior treatment received and distinguishes between surgical or non-surgical approaches. After definitive $\mathrm{RT}$, the definition of BCR is a $>2 \mathrm{ng} / \mathrm{mL}$ increase in the nadir prostate-specific antigen (PSA) level after RT or ADT (Shipley et al. 2017). After prostatectomy, BCR is 


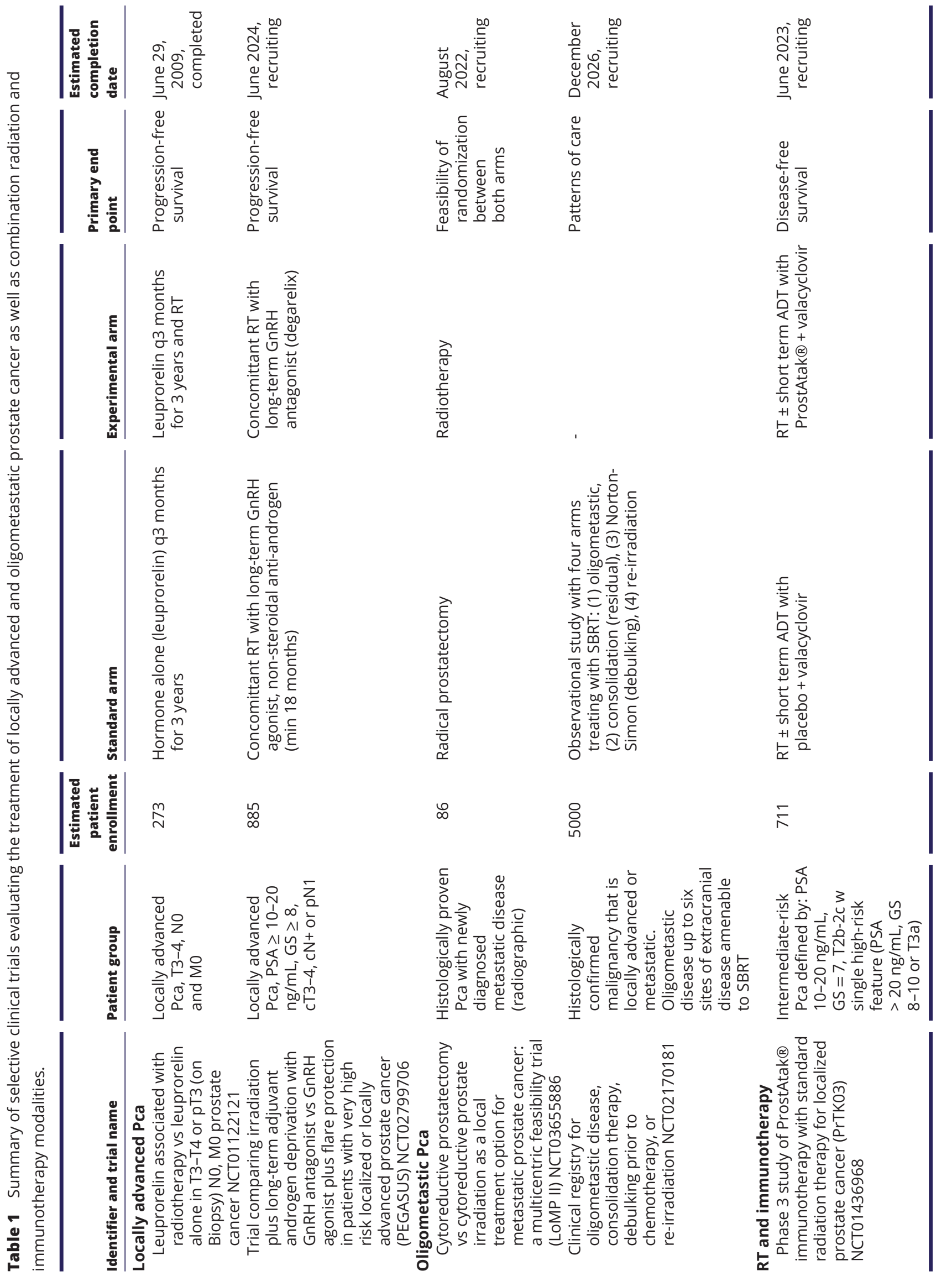



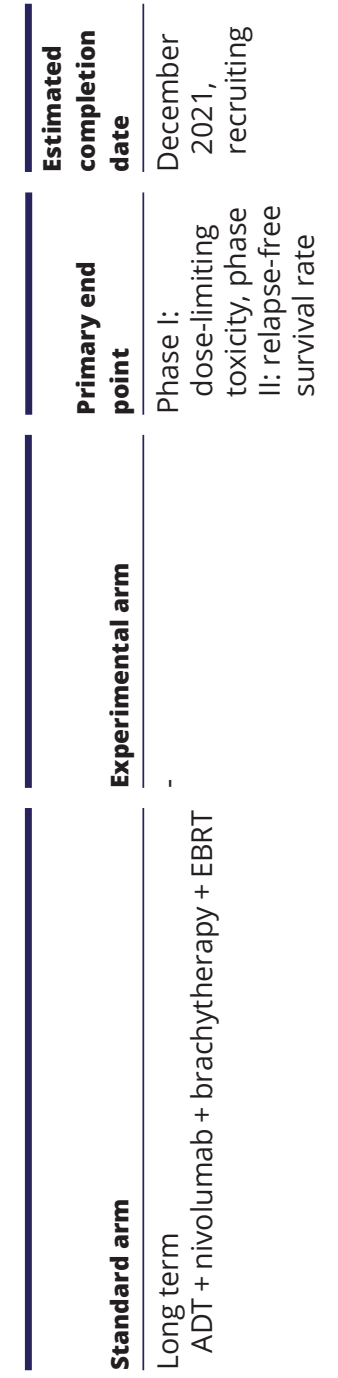

墒

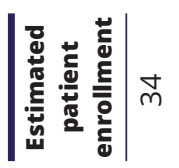

ஜ
ص

离

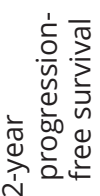

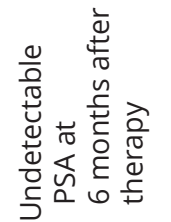

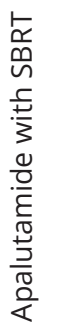

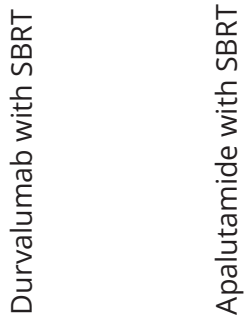

8
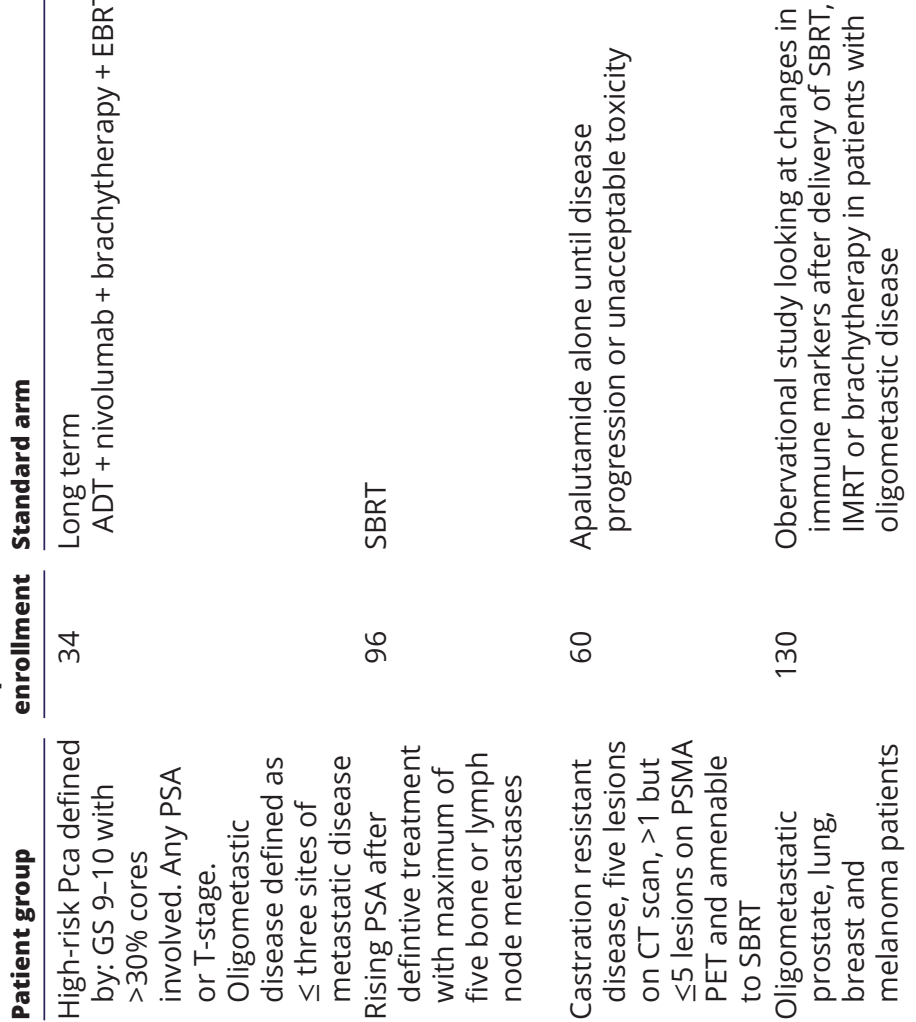
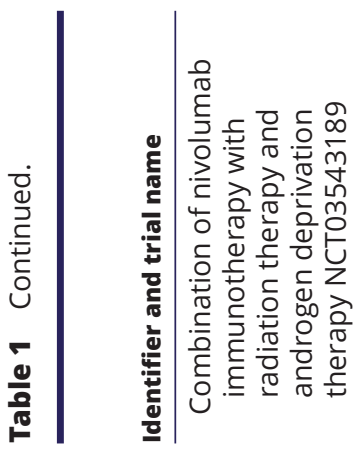

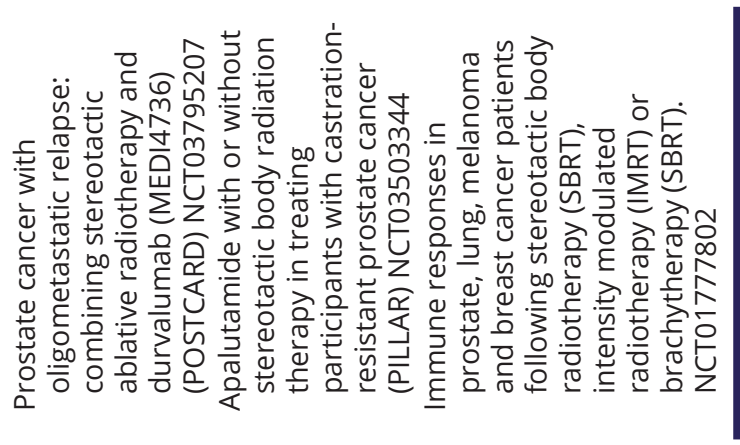

$\stackrel{\wp}{m}$
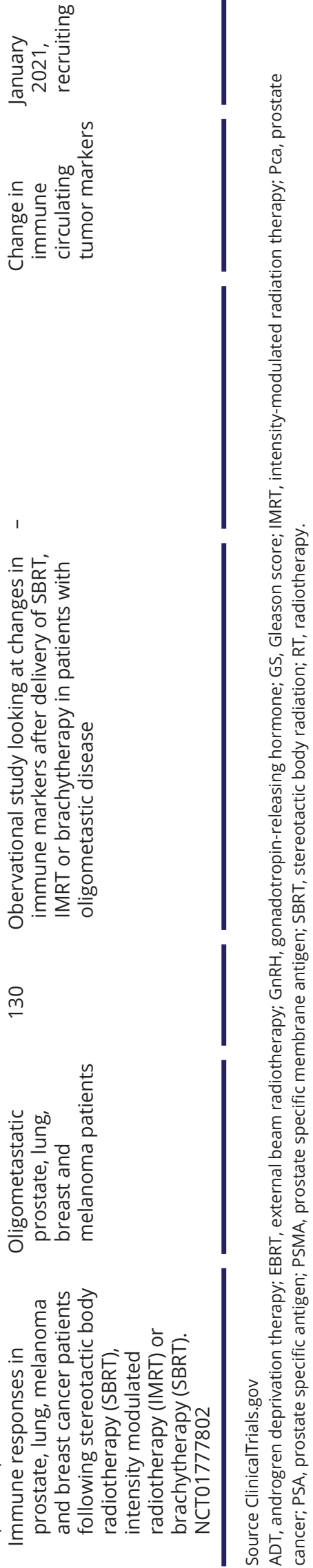
defined as $>0.2 \mathrm{ng} / \mathrm{mL}$ as defined per the EUA, American Society for Radiation Oncology (ASTRO), and American Urological Association (AUA) (Heidenreich et al. 2014, Pisansky et al. 2019). It is important to note that BCR after primary treatment does not necessarily lead to clinically progressive disease. Therefore, the EAU developed a prognostication system based on disease extent and PSA characteristics that stratifies patients into a low-risk or high-risk group (Perera et al. 2020, Van den Broeck et al. 2020). This prognostication system was subsequently validated by Tilki et al. (Tilki et al. 2019). Low-risk BCR among patients after prostatectomy is defined as PSA doubling time $>12$ months and pathological ISUP grade $<4$, whereas, low-risk BCR after definitive RT is defined as PSA doubling time $>18$ months from RT or last luteinizing hormone-releasing hormone (LHRH) treatment and biopsy ISUP grade $<4$.

After confirming BCR, imaging is used to assess for the presence of local or distant disease. However, conventional imaging modalities are limited by low sensitivity. For instance, both scintigraphy and 18-F sodium fluoride (NaF) PET imaging visualize osteoblastic activity and thus do not indicate the full extent of disease activity or volume. Given these limitations, other tracers have been developed to more accurately characterize BCR.

The most common PET tracer used in oncology is 18F-fluorodeoxyglucose (FDG), which visualizes glucose metabolism. However, this has several limitations for prostate cancer, such as the bladder having intense uptake and thereby obscuring visualization of nearby disease and low glucose metabolic pathway use in prostate cancer (Liu et al. 2010). Another tracer is 11C-choline/18F-choline, which visualizes membrane turnover and has shown increased sensitivity; however, it is very PSA-dependent (Giovacchini et al. 2010) and hence limits its utility in the postsurgical setting. Another novel tracer, which received FDA approval in 2016, is 18F-fluciclovine (Axumin). This tracer is an amino acid analog, and though it is also PSAdependent, it has been shown to have a negative predictive value of $100 \%$ with PSA values of more than $1.05 \mathrm{ng} / \mathrm{mL}$ (Schuster et al. 2014). This has made Axumin a valuable tool for informing treatment; for instance, it can widen RT fields because more local disease is visualized or it can help identify distant metastases.

Currently, there is evidence suggesting that prostatespecific membrane antigen (PSMA) PET/CT imaging has the highest sensitivity for detecting recurrent prostate cancer. Briefly, PSMA is a type-II transmembrane glycoprotein that is specifically upregulated among patients with prostate cancer and hence makes it a potential diagnostic and therapeutic target (Chang 2004). PSMA PET has thus become the recommended imaging modality in the setting of rising PSA (Gillessen et al. 2020) to identify sites of failure. For instance, in a retrospective study by Schiller et al (Schiller et al. 2021) using ${ }^{68} \mathrm{Ga}$-PSMA-PET/CT, the study team generated a heat map to represent the most common sites of failure. These sites included nodal regions not covered in the current RTOG pelvic nodal atlas, such as the paraaortal, pararectal, paravesical, preacetabular, presacral, and inguinal regions. Their results suggest that the guidelines may warrant revision for patients with high-risk prostate cancer patients who are undergoing salvage therapy.

The EAU guidelines include recommendations for the treatment of patients with rising PSA levels; specifically, treatment suggestions are given for patients whose PSA levels rise from undetectable range and have pathology showing high-risk features. Evidence supports the use of a multi-modal approach; however, no consensus exists regarding the duration of ADT treatment or timing of RT. Long-term ADT use was supported in RTOG 9601, in which patients with PSA persistence or PSA recurrence who received 2 years of bicalutamide (150 mg daily) with RT were found to have statistically significant improvement in OS compared to those who received RT alone (Shipley et al. 2017). The use of shortterm ADT among patients with rising PSA was assessed in the GETUG-16 study, in which the 6-month use of gonadotropin-releasing hormone (GnRH) along with RT was associated with improvement in PFS, and post-hoc analysis showed improvement in metastasis-free survival (MFS) (Carrie et al. 2016, 2019). More recently, the results from the SPPORT trial (RTOG 0534) also demonstrated the benefit of a short course (4-6 months) of ADT coupled with RT for patients with rising PSA levels (Pollack et al. 2018). However, to date, these data are only available in abstract form. Among patients with rising PSA levels after prostatectomy, the treatment recommendations proposed by the APCC in 2019 are a combination of RT and ADT; despite the lack of consensus, short course ADT is often favored (Gillessen et al. 2020).

The most recently published EUA guidelines propose that the management of BCR after curative intent should be discussed in a multidisciplinary setting and evaluated for a multi-modality approach. In the setting of BCR after RP treatment includes early salvage radiotherapy in men who have experienced two consecutive PSA rises, despite a negative PET/CT (strong recommendation). Similarly, in the setting of BCR following RT multi-modality approaches should be evaluated for highly selected patients (strong recommendation) (Mottet et al. 2021). 


\section{Radiation for oligometastatic prostate cancer}

As progress continues to be made with advanced imaging techniques, more patients with metastatic disease will continue to be identified, and many of these patients may have an oligometastatic disease. The concept of oligometastasis originally developed in the 1990s to describe a distinct stage of disease with limited metastatic tumor burden, allowing for a therapeutic window for treatment with curative rather than palliative intent (Hellman \& Weichselbaum 1995). In 1995, Hellman and Weichselbaum hypothesized that eradicating lowvolume disease with ablative therapy might improve survival (Hellman \& Weichselbaum 1995). Subsequent studies (Ost et al. 2015, 2018) have demonstrated that the ablative treatment of patients with $\leq 3$ lesions led to better prognoses than that of patients with higher volume disease (De Bruycker et al. 2017). To date, there is no consensus on the definition of oligometastatic prostate cancer, as many factors can be considered, such as the location and number of metastases, synchronous vs metachronous metastases, and whether tumors are hormone-sensitive or castrationresistant. In a recent systematic review of literature for oligometastatic prostate cancer found that, while the definition varied with regards to the number of lesions, the most commonly used definition included patients with $\leq 3$ bone metastases (Miura et al. 2020).

Currently, there is a breadth of literature examining the management of oligometastatic disease in prostate cancer, and this research can be classified into two categories: management of de novo metastatic disease or development of metastatic disease after definitive therapy.

Historically, for patients with newly diagnosed metastatic prostate cancer (mPCA), the standard of care has been a systemic therapy with a backbone of androgen deprivation. However, growing evidence is emerging favoring the addition of local therapy such as RT to androgen deprivation for oligometastatic disease (Parker et al. 2018, Boevé et al. 2019, Burdett et al. 2019). One of the first prospective randomized controlled trials to evaluate the management of patients with oligometastatic disease was the HORRAD trial (Boevé et al. 2019). In this study, patients with newly diagnosed mPCA without any prior treatment were randomized to either ADT alone or RT with ADT; the results showed no difference in OS between the two groups (Boevé et al. 2019).

In the STAMPEDE trial, patients with newly diagnosed mPCA were randomized to standard of care (lifelong ADT with or without upfront docetaxel) or standard of care plus RT, with patients stratified based on the metastatic burden. High metastatic burden was considered $\geq 4$ bone metastases with $\geq 1$ metastasis located outside the vertebral body or pelvis, visceral metastasis, or both; all other patients were considered to have the low metastatic burden (Kyriakopoulos et al. 2018). As with the HORRAD study, there was no OS benefit for unselected patients. However, subset analysis showed improved 3-year OS of $81 \%$ vs $73 \%$ for patients with a low metastatic burden who were treated with radiotherapy (HR 0.68 (95\% CI 0.52-0.90); $P=0.007$ ) (Parker et al. 2018). A large meta-analysis on pooled data from the HORRAD, STAMPEDE, and the PEACE trials showed that men with $<4$ bone metastases had a $7 \%$ improvement in 3-year survival when treated with RT and that prostate radiotherapy improved 3-year biochemical progression and failure-free survival by about $10 \%$, but the size of the effect varied by metastatic burden (Burdett et al. 2019). Based on the current evidence, the APCCC recommended that, for patients with a low metastatic burden, RT to the prostate can be offered in conjunction with systemic therapy (Gillessen et al. 2020).

The STOMP trial studied patients who had developed oligometastatic disease, defined as a PSA relapse with up to three extracranial metastases (N1 or M1), after definitive treatment. Patients were randomized to surveillance or metastasis-directed therapy (MDT) in the form of either metastasectomy or stereotactic body radiotherapy (SBRT). At a follow-up of 3 years, ADT-free survival was longer (21 months vs 13 months) for the metastasis-directed therapy group, with similar quality of life between the two arms (Ost et al. 2018). Similarly, in the ORIOLE trial, patients with one to three asymptomatic metastases were randomized to SBRT or observation, and the study showed that SBRT significantly improved PFS ( $P=0.002)$ (Phillips et al. 2020). In this trial, investigators also assessed for T-cell receptor expression and observed that SBRT generated a systemic immune response. Similarly, in a recent study by Siva et al, the authors evaluated the use of stereotactic ablative body radiotherapy (SABR) in a single fraction to metastatic sites and showed that over one-third of patients did not experience progression, were free from ADT at 2 years, had low morbidity, and experienced low impact on quality of life (Siva et al. 2018). Currently, the NCT03655886 trial aims to examine the role of surgery vs RT in the treatment of oligometastatic prostate cancer (Table 1).

As our understanding of oligometastatic disease in prostate cancer continues to evolve, several factors will need further consideration. First, the number and location of lesions as well as chronicity and castration status are all important aspects of the definition of oligometastatic prostate cancer as each of these factors may be prognostic 
for RT benefit. Secondly, there is evidence that metastatic disease involving only the lymph nodes may be a separate entity from a metastatic disease involving other sites (Gillessen et al. 2020). Finally, several clinical trials have demonstrated that disease burden is a key component not only in prognosis but also in treatment options and goals of care (Kyriakopoulos et al. 2018, Ost et al. 2018, Parker et al. 2018, Boevé et al. 2019). An observational study aims to assess the patterns of care in patients with oligometastatic disease by sorting them into four categories: oligometastatic patients treated with SBRT to discrete lesions, consolidation group where SBRT is used on residual disease, Norton-Simon arm where SBRT is used for debulking and finally the re-irradiation group (NCT02170181), which is still in the recruitment stage with expected completion in December 2026 (Table 1).

As we continue to gather more evidence regarding oligometastatic prostate cancer, we will continue to see a shift in the treatment paradigm. Current studies highlight the importance of patient selection and discussion of multimodality approaches. In fact, the EAU now recommends that ADT as monotherapy should not be utilized in patients newly diagnosed with M1 disease as long as they do not have contraindications for combination therapy and have sufficient life expectancy, provided they are willing to accept the increased risk of side effects (Mottet et al. 2021).

The potential acute and late effects of RT should be discussed with patients when considering local therapy in addition to ADT. Acute bowel and bladder toxicity are possible; for reference, patients in the STAMPEDE-RT trial who underwent local RT reported acute bladder toxicity of RTOG grade 3 or $4,5 \%$ of the time and grade 3 or 4 acute bowel toxic effect $1 \%$ of the time-no grade 5 toxic effects were reported (Parker et al. 2018). In the same study, late toxicity of grade 3 or 4 was slightly higher for patients receiving RT compared to ADT alone at $4 \%$ vs $1 \%$; however, this study also showed that patients reporting at least grade 3 or worse adverse events were similar at 6 months, 1 year, and 2 years (Parker et al. 2018).

\section{Radiation and immunotherapy for prostate cancer}

Another area of rapid development in prostate cancer research is the use of immunotherapy, which in the form of checkpoint inhibitors, has revolutionized the treatment paradigm of several advanced malignancies over the past 5 years (Garon et al. 2015, Bellmunt et al. 2017, Wolchok et al. 2017, Motzer et al. 2018).
Unfortunately, the response of prostate cancer to immunotherapy has been less robust than many other solid malignancies (Madan \& Gulley 2019, Zhao et al. 2019). This is believed to be due to several prostate cancer characteristics, including reduced T-cell infiltration, downregulated major histocompatibility complex (MHC) expression, and lower expression of programmed death-ligand (PD-L1) (Patel et al. 2020). A success story in immunotherapy in prostate cancer involves the development of Sipuleucel-T, an autologous dendritic cell vaccine, for mPCa (Kantoff et al. 2010), and more recently and Pembrolizumab (anti-PD1) (Graff et al. 2016). Pembrolizumab gained FDA approval as the only checkpoint inhibitor approved for patients with tumors showing microsatellite instability (MSI) (Le et al. 2017).

The role of immunotherapy alone on mPCa has been evaluated in many trials, here we offer a brief summary. Large phase III clinical trials have failed to show improvement in OS with ipilimumab (a CTLA-4 inhibitor) (Kwon et al. 2014, Beer et al. 2017). However, these trials did demonstrate an acceptable toxicity profile, improved PFS with ipilimumab, and PSA response. Because of the limited benefit of monotherapy, ongoing trials are investigating combination immunotherapy. For instance, the CheckMate 650 trial is evaluating ipilimumab and nivolumab for patients with metastatic castration-resistant prostate cancer (mCRPC) and is comparing cohorts of patients whose diseases have progressed after secondgeneration hormone therapy and have not received chemotherapy to those whose diseases have progressed after taxane-based chemotherapy. Initial results have shown a response rate of $26 \%$ in the chemotherapy-naïve cohort and $10 \%$ in the group who failed taxane-based therapy (Sharma et al. 2020).

Combined therapy with tyrosine kinase inhibitors and checkpoint inhibitors is also being investigated. A recent phase I study (COSMIC-021) evaluated the objective response rate of patients with mCRPC who were treated with cabozantinib (tyrosine kinase inhibitor) with atezolizumab (anti PD-L1 antibody). The results showed an objective response rate of $32 \%$, with $4.5 \%$ of patients had a complete response and $27 \%$ had a partial response (NCT03170960). Other ongoing trials are investigating other combination immunotherapies and evaluating responses in subpopulations with diseases that are thought to be more immunogenic, such as patients with CDK12 mutations (NCT03204812, NCT03570619).

Another emerging promising therapy is chimeric antigen receptor (CAR) T lymphocytes. These cells are engineered to use selected receptors for targeting specific https://erc.bioscientifica.com

https://doi.org/10.1530/ERC-21-0073 (c) 2021 Society for Endocrinology Published by Bioscientifica Ltd. Printed in Great Britain 
cancer antigens. Several phase I trials are ongoing, including those investigating PSMA (NCT04249947).

RT may have the potential to augment immunotherapy. Several reports have demonstrated that RT induces a proinflammatory microenvironment that is thought to increase the likelihood of response to immunotherapies (Di Maggio et al. 2015, Asna et al. 2018, Dallos \& Drake 2018). Growing evidence shows that RT can modulate a tumor to become an immuno-stimulatory milieu by up-regulating surface molecules involved in immune recognition and translocating antigens to the tumorcell surface, rendering them more sensitive to cytotoxic T lymphocyte- (CTL) mediated lysis (Chakraborty et al. 2004, Gameiro et al. 2014, 2016). Preclinical studies have suggested ablative-dose RT between 5 and 20 Gy may have stronger immunostimulatory effects (Patel et al. 2018, Walle et al. 2018). Ablative-dose RT transforms the immunosuppressive tumor microenvironment by increasing CD8+ T-cell infiltration and reducing myeloidderived suppressor cell levels (Filatenkov et al. 2015). Importantly, this was observed only with ablative-dose RT and not with conventional RT. Stereotactic ablative radiotherapy (SABR), with the advantage of delivering ablative doses of RT over a very short period to achieve localized and high-dose distribution, could potentially enhance the immunostimulatory effects of RT in the prostate while minimizing the off-target immunesuppressive effects on peripheral immune cells that occur with conventional daily RT (Filatenkov et al. 2015).

Nivolumab is another anti-PDL-1 MAB that is widely used in several malignancies. In one of the first studies evaluating nivolumab for castration-resistant PCa, none of the 17 patients enrolled demonstrated a significant treatment response (Topalian et al. 2012). However, subsequent studies have shown that there may be dramatic responses to immune checkpoint inhibitors in select populations, in combination with androgen receptor-targeted agents (Carosella et al. 2015, Mahoney et al. 2015, Graff et al. 2016). In a small phase I/II study by Yuan et al, the investigators evaluated the role of nivolumab in combination with ADT and high-dose brachytherapy (HDR) followed by external beam RT and saw that the combination was not only well-tolerated but, on rebiopsy after HDR, 50\% of the patients had no residual tumor in four out of six biopsy cores, and there was increased CD8+ and CD4+ T cell infiltration in tumor samples of early responders (Yuan et al. 2021). Several clinical trials further investigating the combination of RT and immunotherapy are currently recruiting patients (NCT01436968, NCT01436968, NCT03543189, NCT03795207, NCT01777802) (Table 1).

\section{Radioisotope treatment for prostate cancer}

One of the most common causes of morbidity and mortality among patients who progress to mPCA is the development of bone metastases. Though EBRT has long been used for palliation of symptomatic bone lesions, it lacks tumor specificity and often results in increased irradiation to normal surrounding tissues and organs at risk.

Radium-223 is an alpha emitter that has been shown to target bone metastases by selectively binding to areas of high cell turnover (Bruland et al. 2006, Gómez-Veiga et al. 2018). The advantage of alpha emitters is that, because of high linear energy transfer, they are able to deposit more energy at shorter ranges $(<100 \mu \mathrm{m})$ (Bruland et al. 2006). The proposed mechanism of action involves forming complexes with hydroxyapatite in areas of high cell turnover (e.g. bone metastases) using high-energy RT, leading to irreparable DNA damage (Henriksen et al. 2002). The ALSYMPCA trial, in which patients with mCRPC and symptomatic bone lesions were randomized to receive either placebo or radium-223, showed that radium-223 prolonged time to symptomatic bone events, reduced the risk of suffering an event by $34 \%$, and decreased use of EBRT for bone management of bone metastases (Hoskin et al. 2014).

Another class of radioisotope that has been extensively studied for prostate cancer is targeted toward the cell surface protein PSMA. In a large systematic review that summarized the use of the beta emitter lutetium-177, the authors reported an average PSA decline in $75 \%$ of patients, which was supported by radiographic evidence of objective responses and stable disease (Yadav et al. 2019). The VISION trial, which completed accrual in 2018, aims to evaluate the efficacy of 177-Lu-PSMA-617 among patients with mCRPC with PSMA-expressing tumors as determined by PSMA PET imaging (Sartor et al. 2020).

Another agent presently under study is actinium-225 (225-Ac-PSMA-617). This alpha emitter has been shown in a small case series to cause PSA decline and has a good toxicity profile (Kratochwil et al. 2016). Another therapeutic radioisotope is $177-\mathrm{Lu}-\mathrm{J} 591$, which is a radiolabeled humanized MAB. Early phase trials have shown PSA response rates limited by reversible myelosuppression (Tagawa et al. 2010); however, more information is needed with regards to efficacy and safety. (c) 2021 Society for Endocrinology Published by Bioscientifica Ltd. Printed in Great Britain 
Considerable progress has been made in the development of new targeted therapeutics beyond radium-223. However, data is still lacking on their efficacy, toxicity, and combination with standard treatment techniques. At present, there are promising data suggesting that these radioisotopes may be beneficial for carefully selected patients.

\section{Conclusion}

The year 2021 marks the 80th anniversary of ADT for prostate cancer. Though much progress has been made since the incorporation of ADT in the treatment algorithm, prostate cancer remains a significant cause of cancer-related death. While RT, surgery, and ADT remain the backbone of prostate cancer treatment, several recent developments are taking us beyond these therapies. Improvements in prostate cancer-specific imaging modalities are improving staging and evaluation, allowing for better informed treatment planning. Some of these newer technologies are allowing physicians to diagnose patients with oligometastatic disease and through the use of ablative therapies treat these patients with curative rather than palliative intent. Combination immunotherapies augmented by RT show promise to improve clinical outcomes. Finally, radioisotopes have been shown to effectively target and treat prostate cancer with high tumor specificity and remain a potent therapeutic option for select patients.

\section{Declaration of interest}

The authors declare that there is no conflict of interest that could be perceived as prejudicing the impartiality of this review.

\section{Funding}

This work did not receive any specific grants from any funding agency in the public, commercial or not-for-profit sector.

\section{References}

Abdollah F, Dalela D, Sood A, Keeley J, Alanee S, Briganti A, Montorsi F, Peabody JO \& Menon M 2018 Impact of adjuvant radiotherapy in node-positive prostate cancer patients: the importance of patient selection. European Urology $\mathbf{7 4}$ 253-256. (https://doi.org/10.1016/j. eururo.2018.04.017)

Asna N, Livoff A, Batash R, Debbi R, Schaffer P, Rivkind T \& Schaffer M 2018 Radiation therapy and immunotherapy-a potential combination in cancer treatment. Current Oncology 25 e454-e460. (https://doi. org/10.3747/co.25.4002)
Beer TM, Kwon ED, Drake CG, Fizazi K, Logothetis C, Gravis G, Ganju V, Polikoff J, Saad F, Humanski P, et al. 2017 Randomized, double-blind, phase III trial of ipilimumab versus placebo in asymptomatic or minimally symptomatic patients with metastatic chemotherapy-naive castration-resistant prostate cancer. Journal of Clinical Oncology 35 40-47. (https://doi.org/10.1200/JCO.2016.69.1584)

Bellmunt J, De Wit R, Vaughn DJ, Fradet Y, Lee JL, Fong L, Vogelzang NJ, Climent MA, Petrylak DP, Choueiri TK, et al. 2017 Pembrolizumab as second-line therapy for advanced urothelial carcinoma. New England Journal of Medicine 376 1015-1026. (https://doi.org/10.1056/ NEJMoa1613683)

Boevé LMS, Hulshof MCCM, Vis AN, Zwinderman AH, Twisk JWR, Witjes WPJ, Delaere KPJ, Moorselaar RJAV, Verhagen PCMS \& Van Andel G 2019 Effect on survival of androgen deprivation therapy alone compared to androgen deprivation therapy combined with concurrent radiation therapy to the prostate in patients with primary bone metastatic prostate cancer in a prospective randomised clinical trial: data from the HORRAD trial. European Urology 75 410-418. (https://doi.org/10.1016/j.eururo.2018.09.008)

Bolla M, De Reijke TM, Van Tienhoven G, Van Den Bergh AC, Oddens J, Poortmans PM, Gez E, Kil P, Akdas A, Soete G, et al. 2009 Duration of androgen suppression in the treatment of prostate cancer. New England Journal of Medicine 360 2516-2527. (https://doi.org/10.1056/ NEJMoa0810095)

Bolla M, Van Tienhoven G, Warde P, Dubois JB, Mirimanoff RO, Storme G, Bernier J, Kuten A, Sternberg C, Billiet I, et al. 2010 External irradiation with or without long-term androgen suppression for prostate cancer with high metastatic risk: 10-year results of an EORTC randomised study. Lancet: Oncology 11 1066-1073. (https://doi.org/10.1016/S14702045(10)70223-0)

Bruland ØS, Nilsson S, Fisher DR \& Larsen RH 2006 High-linear energy transfer irradiation targeted to skeletal metastases by the $\alpha$-emitter \&lt;sup\&gt;223\&lt;/sup\&gt;ra: adjuvant or alternative to conventional modalities? Clinical Cancer Research 12 6250s-6257s. (https://doi. org/10.1158/1078-0432.CCR-06-0841)

Burdett S, Boevé LM, Ingleby FC, Fisher DJ, Rydzewska LH, Vale CL, Van Andel G, Clarke NW, Hulshof MC, James ND, et al. 2019 Prostate radiotherapy for metastatic hormone-sensitive prostate cancer: a STOPCAP systematic review and meta-analysis. European Urology $\mathbf{7 6}$ 115-124. (https://doi.org/10.1016/j.eururo.2019.02.003)

Carosella ED, Ploussard G, Lemaoult J \& Desgrandchamps F 2015 A systematic review of immunotherapy in urologic cancer: evolving roles for targeting of CTLA-4, PD-1/PD-L1, and HLA-G. European Urology 68 267-279. (https://doi.org/10.1016/j.eururo.2015.02.032)

Carrie C, Hasbini A, De Laroche G, Richaud P, Guerif S, Latorzeff I, Supiot S, Bosset M, Lagrange JL, Beckendorf V, et al. 2016 Salvage radiotherapy with or without short-term hormone therapy for rising prostate-specific antigen concentration after radical prostatectomy. (GETUG-AFU 16): a randomised, multicentre, open-label phase 3 trial. Lancet: Oncology 17 747-756. (https://doi.org/10.1016/S1470-2045(16)00111-X)

Carrie C, Magné N, Burban-Provost P, Sargos P, Latorzeff I, Lagrange JL, Supiot S, Belkacemi Y, Peiffert D, Allouache N, et al. 2019 Short-term androgen deprivation therapy combined with radiotherapy as salvage treatment after radical prostatectomy for prostate cancer (GETUG-AFU 16): a 112-month follow-up of a phase 3, randomised trial. Lancet: Oncology 20 1740-1749. (https://doi.org/10.1016/S1470-2045(19)30486-3)

Chakraborty M, Abrams SI, Coleman CN, Camphausen K, Schlom J \& Hodge JW 2004 External beam radiation of tumors alters phenotype of tumor cells to render them susceptible to vaccine-mediated T-cell killing. Cancer Research 64 4328-4337. (https://doi.org/10.1158/00085472.CAN-04-0073)

Chang SS 2004 Overview of prostate-specific membrane antigen. Reviews in Urology 6(Supplement 10) S13-S18.

Dallos MC \& Drake CG 2018 Blocking PD-1/PD-L1 in genitourinary malignancies: to immunity and beyond. Cancer Journal 24 20-30. (https://doi.org/10.1097/PPO.0000000000000302) (c) 2021 Society for Endocrinology Published by Bioscientifica Ltd. Printed in Great Britain 
De Bruycker A, Lambert B, Claeys T, Delrue L, Mbah C, De Meerleer G, Villeirs G, De Vos F, De Man K, Decaestecker K, et al. 2017 Prevalence and prognosis of low-volume, oligorecurrent, hormone-sensitive prostate cancer amenable to lesion ablative therapy. BJU International 120 815-821. (https://doi.org/10.1111/bju.13938)

Di Maggio FM, Minafra L, Forte GI, Cammarata FP, Lio D, Messa C, Gilardi MC \& Bravatà V 2015 Portrait of inflammatory response to ionizing radiation treatment. Journal of Inflammation 12 14. (https:// doi.org/10.1186/s12950-015-0058-3)

Filatenkov A, Baker J, Mueller AM, Kenkel J, Ahn GO, Dutt S, Zhang N, Kohrt H, Jensen K, Dejbakhsh-Jones S, et al. 2015 Ablative tumor radiation can change the tumor immune cell microenvironment to induce durable complete remissions. Clinical Cancer Research 21 3727-3739. (https://doi.org/10.1158/1078-0432.CCR-14-2824)

Gameiro SR, Ardiani A, Kwilas A \& Hodge JW 2014 Radiation-induced survival responses promote immunogenic modulation to enhance immunotherapy in combinatorial regimens. Oncoimmunology 3 e28643. (https://doi.org/10.4161/onci.28643)

Gameiro SR, Malamas AS, Bernstein MB, Tsang KY, Vassantachart A, Sahoo N, Tailor R, Pidikiti R, Guha CP, Hahn SM, et al. 2016 Tumor cells surviving exposure to proton or photon radiation share a common immunogenic modulation signature, rendering them more sensitive to $\mathrm{T}$ cell-mediated killing. International Journal of Radiation Oncology, Biology, Physics 95 120-130. (https://doi.org/10.1016/j. ijrobp.2016.02.022)

Garon EB, Rizvi NA, Hui R, Leighl N, Balmanoukian AS, Eder JP, Patnaik A, Aggarwal C, Gubens M, Horn L, et al. 2015 Pembrolizumab for the treatment of non-small-cell lung cancer. New England Journal of Medicine 372 2018-2028. (https://doi.org/10.1056/ NEJMoa1501824)

Gillessen S, Attard G, Beer TM, Beltran H, Bjartell A, Bossi A, Briganti A, Bristow RG, Chi KN, Clarke N, et al. 2020 Management of patients with advanced prostate cancer: report of the advanced prostate cancer consensus Conference 2019. European Urology 77 508-547. (https://doi. $\operatorname{org} / 10.1016 / j$.eururo.2020.01.012)

Giovacchini G, Picchio M, Coradeschi E, Bettinardi V, Gianolli L, Scattoni V, Cozzarini C, Di Muzio N, Rigatti P, Fazio F, et al. 2010 Predictive factors of $[(11) \mathrm{C}]$ choline PET/CT in patients with biochemical failure after radical prostatectomy. European Journal of Nuclear Medicine and Molecular Imaging 37 301-309. (https://doi. org/10.1007/s00259-009-1253-3)

Gómez-Veiga F, Álvarez-Ossorio JL, Carballido-Rodríguez J, Juárez-Soto A, Rodríguez-Antolín A \& Cozar-Olmo JM 2018 Radium-223 for the treatment of metastatic castration-resistant prostate cancer: a window of opportunity. Actas Urologicas Españolas 42 616-624. (https://doi. org/10.1016/j.acuro.2018.05.004)

Graff JN, Alumkal JJ, Drake CG, Thomas GV, Redmond WL, Farhad M, Cetnar JP, Ey FS, Bergan RC, Slottke R, et al. 2016 Early evidence of anti-PD-1 activity in enzalutamide-resistant prostate cancer. Oncotarget 7 52810-52817. (https://doi.org/10.18632/oncotarget.10547)

Heidenreich A, Bastian PJ, Bellmunt J, Bolla M, Joniau S, Van Der Kwast T, Mason M, Matveev V, Wiegel T, Zattoni F, et al. 2014 EAU guidelines on prostate cancer. Part II: treatment of advanced, relapsing, and castration-resistant prostate cancer. European Urology 65 467-479. (https://doi.org/10.1016/j.eururo.2013.11.002)

Hellman S \& Weichselbaum RR 1995 Oligometastases. Journal of Clinical Oncology 13 8-10. (https://doi.org/10.1200/JCO.1995.13.1.8)

Henriksen G, Breistøl K, Bruland ØS, Fodstad Ø \& Larsen RH 2002 Significant antitumor effect from bone-seeking, alpha-particleemitting (223)Ra demonstrated in an experimental skeletal metastases model. Cancer Research 62 3120-3125.

Hofman MS, Murphy DG, Williams SG, Nzenza T, Herschtal A, Lourenco RA, Bailey DL, Budd R, Hicks RJ, Francis RJ, et al. 2018 A prospective randomized multicentre study of the impact of gallium- 68 prostate-specific membrane antigen (PSMA) PET/CT imaging for staging high-risk prostate cancer prior to curative-intent surgery or radiotherapy (proPSMA study): clinical trial protocol. BJU International 122 783-793. (https://doi.org/10.1111/bju.14374)

Hoskin P, Sartor O, O'sullivan JM, Johannessen DC, Helle SI, Logue J, Bottomley D, Nilsson S, Vogelzang NJ, Fang F, et al. 2014 Efficacy and safety of radium-223 dichloride in patients with castration-resistant prostate cancer and symptomatic bone metastases, with or without previous docetaxel use: a prespecified subgroup analysis from the randomised, double-blind, phase 3 ALSYMPCA trial. Lancet: Oncology 15 1397-1406. (https://doi.org/10.1016/S1470-2045(14)70474-7)

Jones CU, Hunt D, Mcgowan DG, Amin MB, Chetner MP, Bruner DW, Leibenhaut MH, Husain SM, Rotman M, Souhami L, et al. 2011 Radiotherapy and short-term androgen deprivation for localized prostate cancer. New England Journal of Medicine 365 107-118. (https:// doi.org/10.1056/NEJMoa1012348)

Kantoff PW, Higano CS, Shore ND, Berger ER, Small EJ, Penson DF, Redfern CH, Ferrari AC, Dreicer R, Sims RB, et al. 2010 Sipuleucel-T immunotherapy for castration-resistant prostate cancer. New England Journal of Medicine 363 411-422. (https://doi.org/10.1056/ NEJMoa1001294)

Kratochwil C, Bruchertseifer F, Giesel FL, Weis M, Verburg FA, Mottaghy F, Kopka K, Apostolidis C, Haberkorn U \& Morgenstern A 2016 225Ac-PSMA-617 for PSMA-targeted $\alpha$-radiation therapy of metastatic castration-resistant prostate cancer. Journal of Nuclear Medicine $\mathbf{5 7}$ 1941-1944. (https://doi.org/10.2967/jnumed.116.178673)

Kwon ED, Drake CG, Scher HI, Fizazi K, Bossi A, Van Den Eertwegh AJ, Krainer M, Houede N, Santos R, Mahammedi H, et al. 2014 Ipilimumab versus placebo after radiotherapy in patients with metastatic castration-resistant prostate cancer that had progressed after docetaxel chemotherapy (CA184-043): a multicentre, randomised, double-blind, phase 3 trial. Lancet: Oncology 15 700-712. (https://doi.org/10.1016/ S1470-2045(14)70189-5)

Kyriakopoulos CE, Chen YH, Carducci MA, Liu G, Jarrard DF, Hahn NM, Shevrin DH, Dreicer R, Hussain M, Eisenberger M, et al. 2018 Chemohormonal therapy in metastatic hormone-sensitive prostate cancer: long-term survival analysis of the randomized phase III E3805 CHAARTED trial. Journal of Clinical Oncology 36 1080-1087. (https:// doi.org/10.1200/JCO.2017.75.3657)

Le DT, Durham JN, Smith KN, Wang H, Bartlett BR, Aulakh LK, Lu S, Kemberling H, Wilt C, Luber BS, et al. 2017 Mismatch repair deficiency predicts response of solid tumors to PD-1 blockade. Science $\mathbf{3 5 7}$ 409-413. (https://doi.org/10.1126/science.aan6733)

Liu Y, Zuckier LS \& Ghesani NV 2010 Dominant uptake of fatty acid over glucose by prostate cells: a potential new diagnostic and therapeutic approach. Anticancer Research 30 369-374.

Madan RA \& Gulley JL 2019 Finding an immunologic beachhead in the prostate cancer microenvironment. Journal of the National Cancer Institute 111 219-220. (https://doi.org/10.1093/jnci/djy145)

Mahoney KM, Rennert PD \& Freeman GJ 2015 Combination cancer immunotherapy and new immunomodulatory targets. Nature Reviews: Drug Discovery 14 561-584. (https://doi.org/10.1038/nrd4591)

Miura N, Pradere B, Mori K, Mostafaei H, Quhal F, Misrai V, D'andrea D, Albisinni S, Papalia R, Saika T, et al. 2020 Metastasis-directed therapy and prostate-targeted therapy in oligometastatic prostate cancer: a systematic review. Minerva Urologica e Nefrologica 72 531-542. (https:// doi.org/10.23736/S0393-2249.20.03779-0)

Mottet N, BJ, Briers E, Bolla M, Bourke L, Cornford P, De Santis M, Henry A, Joniau S, Lam T, et al. 2021 EAU - ESTRO - ESUR - SIOG guidelines on prostate cancer. Edn. presented at the EAU Annual Congress Milan 2021 Arnhem, The Netherlands, EAU Guidelines Office. (available at: https://uroweb.org/guideline/prostate-cancer/)

Motzer RJ, Tannir NM, Mcdermott DF, Aren Frontera O, Melichar B, Choueiri TK, Plimack ER, Barthelemy P, Porta C, George S, et al. 2018 https://erc.bioscientifica.com https://doi.org/10.1530/ERC-21-0073 (c) 2021 Society for Endocrinology Published by Bioscientifica Ltd. Printed in Great Britain 
Nivolumab plus ipilimumab versus sunitinib in advanced renal-cell carcinoma. New England Journal of Medicine 378 1277-1290. (https:// doi.org/10.1056/NEJMoa1712126)

Ost P, Bossi A, Decaestecker K, De Meerleer G, Giannarini G, Karnes RJ, Roach M, 3RD \& Briganti A 2015 Metastasis-directed therapy of regional and distant recurrences after curative treatment of prostate cancer: a systematic review of the literature. European Urology $\mathbf{6 7}$ 852-863. (https://doi.org/10.1016/j.eururo.2014.09.004)

Ost P, Reynders D, Decaestecker K, Fonteyne V, Lumen N, De Bruycker A, Lambert B, Delrue L, Bultijnck R, Claeys T, et al. 2018 Surveillance or metastasis-directed therapy for oligometastatic prostate cancer recurrence: A prospective, randomized, multicenter Phase II trial. Journal of Clinical Oncology 36 446-453. (https://doi.org/10.1200/ JCO.2017.75.4853)

Parker CC, James ND, brawley CD, clarke NW, Hoyle AP, Ali A, Ritchie AWS, Attard G, Chowdhury S, Cross W, et al. 2018 Radiotherapy to the primary tumour for newly diagnosed, metastatic prostate cancer (STAMPEDE): a randomised controlled phase 3 trial. Lancet 392 23532366. (https://doi.org/10.1016/S0140-6736(18)32486-3)

Patel RB, Baniel CC, Sriramaneni RN, Bradley K, Markovina S \& Morris ZS 2018 Combining brachytherapy and immunotherapy to achieve in situ tumor vaccination: a review of cooperative mechanisms and clinical opportunities. Brachytherapy 17 995-1003. (https://doi. org/10.1016/j.brachy.2018.07.004)

Patel D, Mckay R \& Parsons JK 2020 Immunotherapy for localized prostate cancer: the next frontier? Urologic Clinics of North America 47 443-456. (https://doi.org/10.1016/j.ucl.2020.07.008)

Perera M, Papa N, Roberts M, Williams M, Udovicich C, Vela I, Christidis D, Bolton D, Hofman MS, Lawrentschuk N, et al. 2020 Gallium-68 prostate-specific membrane antigen positron emission tomography in advanced prostate cancer-updated diagnostic utility, sensitivity, specificity, and distribution of prostate-specific membrane antigen-avid lesions: a systematic review and meta-analysis. European Urology 77 403-417. (https://doi.org/10.1016/j.eururo.2019.01.049)

Perlmutter MA \& Lepor H 2007 Androgen deprivation therapy in the treatment of advanced prostate cancer. Reviews in Urology 9(Supplement 1) S3-S8.

Phillips R, Shi WY, Deek M, Radwan N, Lim SJ, Antonarakis ES, Rowe SP, Ross AE, Gorin MA, Deville C, et al. 2020 Outcomes of observation vs stereotactic ablative radiation for oligometastatic prostate cancer: the ORIOLE Phase 2 randomized clinical trial. Journal of the American Medical Association Oncology 6 650-659. (https://doi.org/10.1001/ jamaoncol.2020.0147)

Pilepich MV, Winter K, Lawton CA, Krisch RE, Wolkov HB, Movsas B, Hug EB, Asbell SO \& Grignon D 2005 Androgen suppression adjuvant to definitive radiotherapy in prostate carcinoma--long-term results of phase III RTOG 85-31. International Journal of Radiation Oncology, Biology, Physics 61 1285-1290. (https://doi.org/10.1016/j. ijrobp.2004.08.047)

Pisansky TM, Thompson IM, Valicenti RK, D'amico AV \& Selvarajah S 2019 Adjuvant and salvage radiotherapy after prostatectomy: ASTRO/AUA guideline amendment 2018-2019. Journal of Urology 202 533-538. (https://doi.org/10.1097/JU.0000000000000295)

Pollack A, Karrison TG, Balogh AG, Low D, Bruner DW, Wefel JS, Gomella LG, Vigneault E, Michalski JM, Angyalfi S, et al. 2018 Short term androgen deprivation therapy without or with pelvic lymph node treatment added to prostate bed only salvage radiotherapy: the NRG Oncology/RTOG 0534 SPPORT trial. International Journal of Radiation Oncology, Biology, Physics 102 1605. (https://doi. org/10.1016/j.ijrobp.2018.08.052)

Preisser F, Chun FKH, Pompe RS, Heinze A, Salomon G, Graefen M, Huland H \& Tilki D 2019 Persistent prostate-specific antigen After radical prostatectomy and its impact on oncologic outcomes. European Urology 76 106-114. (https://doi.org/10.1016/j.eururo.2019.01.048)

Roach M, 3RD, Hanks G, Thames H, Schellhammer P, Shipley WU, Sokol GH \& Sandler H 2006 Defining biochemical failure following radiotherapy with or without hormonal therapy in men with clinically localized prostate cancer: recommendations of the RTOGASTRO Phoenix Consensus Conference. International Journal of Radiation Oncology, Biology, Physics 65 965-974. (https://doi. org/10.1016/j.ijrobp.2006.04.029)

Sartor AO, Morris MJ, Messman R \& Krause BJ 2020 VISION: an international, prospective, open-label, multicenter, randomized phase III study of 177Lu-PSMA-617 in the treatment of patients with progressive PSMA-positive metastatic castration-resistant prostate cancer (mCRPC) Journal of Clinical Oncology 38 TPS259-TPS259. (https://doi.org/10.1200/JCO.2020.38.6_suppl.TPS259)

Schiller K, Stöhrer L, Düsberg M, Borm K, Devecka M, Vogel MME, Tauber R, Heck MM, Rauscher I, Eiber M, et al. 2021 PSMA-PET/ CT-based lymph node atlas for prostate cancer patients recurring After primary treatment: clinical implications for salvage radiation therapy. European Urology Oncology 4 73-83. (https://doi.org/10.1016/j. euo.2020.04.004)

Schuster DM, Nieh PT, Jani AB, Amzat R, Bowman FD, Halkar RK, Master VA, Nye JA, Odewole OA, Osunkoya AO, et al. 2014 Anti-3[(18)F]FACBC positron emission tomography-computerized tomography and (111)In-capromab pendetide single photon emission computerized tomography-computerized tomography for recurrent prostate carcinoma: results of a prospective clinical trial. Journal of Urology 191 1446-1453. (https://doi.org/10.1016/j. juro.2013.10.065)

Sharma P, Pachynski RK, Narayan V, Fléchon A, Gravis G, Galsky MD, Mahammedi H, Patnaik A, Subudhi SK, Ciprotti M, et al. 2020 Nivolumab plus ipilimumab for metastatic castration-resistant prostate cancer: preliminary analysis of patients in the CheckMate 650 trial. Cancer Cell 38 489.e3-499.e3. (https://doi.org/10.1016/j. ccell.2020.08.007)

Shipley WU, Seiferheld W, Lukka HR, Major PP, Heney NM, Grignon DJ, Sartor O, Patel MP, Bahary JP, Zietman AL, et al. 2017 Radiation with or without antiandrogen therapy in recurrent prostate cancer. New England Journal of Medicine 376 417-428. (https://doi.org/10.1056/ NEJMoa1607529)

Siva S, Bressel M, Murphy DG, Shaw M, Chander S, Violet J, Tai KH, Udovicich C, Lim A, Selbie L, et al. 2018 Stereotactic abative body radiotherapy (SABR) for oligometastatic prostate cancer: A prospective clinical trial. European Urology $\mathbf{7 4}$ 455-462. (https://doi.org/10.1016/j. eururo.2018.06.004)

Tagawa ST, Beltran H, Vallabhajosula S, Goldsmith SJ, Osborne J, Matulich D, Petrillo K, Parmar S, Nanus DM \& Bander NH 2010 Antiprostate-specific membrane antigen-based radioimmunotherapy for prostate cancer. Cancer 116(Supplement) 1075-1083. (https://doi. org/10.1002/cncr.24795)

Tilki D, Preisser F, Graefen M, Huland H \& Pompe RS 2019 External validation of the European Association of Urology biochemical recurrence risk groups to predict metastasis and mortality after radical prostatectomy in a European cohort. European Urology 75 896-900. (https://doi.org/10.1016/j.eururo.2019.03.016)

Topalian SL, Hodi FS, Brahmer JR, Gettinger SN, Smith DC, Mcdermott DF, Powderly JD, Carvajal RD, Sosman JA, Atkins MB, et al. 2012 Safety, activity, and immune correlates of anti-PD-1 antibody in cancer. New England Journal of Medicine 366 2443-2454. (https://doi.org/10.1056/ NEJMoa1200690)

Touijer KA, Karnes RJ, Passoni N, Sjoberg DD, Assel M, Fossati N, Gandaglia G, Eastham JA, Scardino PT, Vickers A, et al. 2018 Survival outcomes of men with lymph node-positive prostate cancer after radical prostatectomy: A comparative analysis of different postoperative management strategies. European Urology 73 890-896. (https://doi.org/10.1016/j.eururo.2017.09.027)

Van Den Broeck T, Van Den Bergh RCN, Briers E, Cornford P, Cumberbatch M, Tilki D, De Santis M, Fanti S, Fossati N, Gillessen S, et al. 2020 Biochemical recurrence in prostate cancer: the European Association of Urology prostate cancer guidelines panel 
recommendations. European Urology Focus 6 231-234. (https://doi. org/10.1016/j.euf.2019.06.004)

Walle T, Martinez Monge R, Cerwenka A, Ajona D, Melero I \& Lecanda F 2018 Radiation effects on antitumor immune responses: current perspectives and challenges. Therapeutic Advances in Medical Oncology 10 1758834017742575. (https://doi.org/10.1177/1758834017742575)

Wolchok JD, Chiarion-Sileni V, Gonzalez R, Rutkowski P, Grob JJ, Cowey CL, Lao CD, Wagstaff J, Schadendorf D, Ferrucci PF, et al. 2017 Overall survival with combined nivolumab and ipilimumab in advanced melanoma. New England Journal of Medicine 377 1345-1356. (https://doi.org/10.1056/NEJMoa1709684)

Yadav MP, Ballal S, Sahoo RK, Dwivedi SN \& Bal C 2019 Radioligand therapy with 177Lu-PSMA for metastatic castration-resistant prostate cancer: a systematic review and meta-analysis. AJR: American Journal of Roentgenology 213 275-285. (https://doi.org/10.2214/AJR.18.20845) Yuan Z, Fernandez D, Dhillon J, Abraham-Miranda J, Awasthi S, Kim Y, Zhang J, Jain R, Serna A, Pow-Sang JM, et al. 2021 Proof-of-principle phase I results of combining nivolumab with brachytherapy and external beam radiation therapy for Grade Group 5 prostate cancer: safety, feasibility, and exploratory analysis. Prostate Cancer and Prostatic Diseases 24 140-149. (https://doi.org/10.1038/s41391-020-0254-y) Zhao SG, Lehrer J, Chang SL, Das R, Erho N, Liu Y, Sjöström M, Den RB, Freedland SJ, Klein EA, et al. 2019 The immune landscape of prostate cancer and nomination of PD-L2 as a potential therapeutic target. Journal of the National Cancer Institute 111 301-310. (https://doi org/10.1093/jnci/djy141)

Received in final form 24 May 2021

Accepted 1 June 2021

Accepted Manuscript published online 1 June 2021 (c) 2021 Society for Endocrinology Published by Bioscientifica Ltd. Printed in Great Britain 